8 Rose D, Leese M, Oliver D, Sidhu R, Bennewith O, Priebe S, et al. A comparison of participant information elicited by service user and non-service user researchers. Psychiatr Serv 2011; 62: 210

9 Callard F, Wykes T. Mental health and perceptions of biomarker research - possible effects on participation. J Ment Health 2008; 17: 1-7.

10 Thornicroft G, Tansella M. Growing recognition of the importance of service user involvement in mental health service planning and evaluation. Epidemio Psichiatr SOC 2005; 14: 1-3.

11 Tait $\mathrm{L}$, Lester $\mathrm{H}$. Encouraging user involvement in mental health services. Adv Psychiatr Treat 2005; 11: 168-75.

12 Minogue V, Boness J, Brown A, Girdlestone J. The impact of service user involvement in research. Int J Health Care Qual Assur 2005; 18: 103-12.

13 Mental Health Research Network. An Evaluation of Service User Involvement in Studies Adopted by the Mental Health Research Network. Mental Health Research Network, 2012
14 National Institute for Health Research. Performance Report Quarter 3 2012/ 13 (October to December 2012). NIHR, 2013.

15 Mental Health Research Funders' Group. Strategic Analysis of UK Mental Health Research Funding. Mental Health Research Funders' Group, 2005

16 Gunderson JG, Stout RL, McGlashan TH, Shea MT, Morey LC, Grilo CM, et al. Ten-year course of borderline personality disorder: psychopathology and function from the Collaborative Longitudinal Personality Disorders study. Arch Gen Psychiatry 2011; 68: 827-37.

17 Medicines for Children Research Network. Young Person's Advisory Group Progress Report 2009-2011. Medicines for Children Research Network, 2011.

18 Tarpey M. Public Involvement in Research Applications to the National Research Ethics Service. INVOLVE, 2011.

19 Trivedi $\mathrm{P}$, Wykes T. From passive subjects to equal partners: qualitative review of user involvement in research. Br J Psychiatry 2002; 181: 468-72.

\title{
Social avatar
}

\section{David Brunskill}

The first avatars (used to represent the self on computers) used basic animation. However, online social arenas are sophisticated. By selectively posting written/visual material, individuals can self-manage image, effectively creating a social avatar. While there is growing awareness of the need to distinguish between 'private' and 'public' aspects of posted material, the psychological effects of social avatars are unrecognised. The selective creation and maintenance of a social avatar is most likely to affect individuals who already struggle to integrate aspects of their personality, behaviour and psyche. This opportunity for further compartmentalisation therefore reinforces divisions in the self, with unhelpful consequences. 